\title{
Radiotherapy Measurements Using Fricke Gel Dosimeter
}

\author{
M.I. El Gohary, Y.S. Shabban", A.E. Ahmed ${ }^{* *}$, M.H. Abdel \\ Gawad, O.S. Desouky* \\ Biophysics Branch, Physics Department, Faculty of Science, \\ Al-Azhar University; *National Center for Radiation Research \\ and Technology and ${ }^{* *}$ Medical Physics Unit, Ain-Shams \\ Hospital, Ain-Shams University, Cairo, Egypt.
}

\begin{abstract}
THE RADIOTHERAPY is mainly used in cancer treatment. The treatment machines are divided into two types, one is depending on natural sources (e.g cobalt 60 machine) which delivers gamma ray and the other is depending on artificial source such as linear accelerator machine (Linac), they both deliver electron and X-ray with different energies. To calculate treatment dose or to setup a radiotherapy plan for a patient with suitable energy, some parameters must be measured to check the quality and the quantity of this energy. In present study, dosimetric parameters, such as calibration curve, open and wedged beam profiles and total scatter factors, are evaluated for two mega voltage photons "X-ray" ( 6 \& $15 \mathrm{MV}$ ) and two electrons (6 \& $15 \mathrm{MeV}$ ) beam energies using a chemical dosimeters such as Fricke Xylenol Gel dosimeter (FXG). The measurements are compared with other dosimeters such as ionization chambers and daily QA machine. The aim of this work is to evaluate the FXG to be used in measuring these parameters and acts as alternative dosimeter used in daily quality assurance checks. The results show that the differences of these parameters between the standard dosimeters (Ionization chambers and daily QA machine) are not more than 3\%.
\end{abstract}

Keywords: Radiotherapy, Dosimetric parameters, Beam profiles, Output factor, Fricke Xylenol Gel, Ionization chamber.

The radiotherapy is one of the methods that is used for tumor treatment, it includes ionizing radiation to control cancer cells. Because of the radiation hazard, it is necessary to save the normal tissues surrounding cancer cells. The suitable dose distribution is depending on some physical parameters involved in the quality and quantity of treatment by 0.9 ionizing radiation. In radiotherapy, to ensure that the prescribed dose will be delivered to the patient, the radiation beam dosimetry should be guided by reference protocols ${ }^{(1)}$. One of the recommendations of performing dosimetry is using water phantom (or equivalent water such as solid water or polymethyl methacrylate (PMMA) slabs) and ionization chambers as the reference dosimeters for a particular energy, radiation type, and geometry. The dosimetry system aims to obtaining an absorbed dose of a specific radiation beam and evaluates the related dosimetric parameters. These parameters are considered for the patient radiotherapy treatment to achieve an 
accurate specific radiation, to deliver the prescribed absorbed dose. The percentage depth dose, beam profiles (for open and wedged beams) and output factor are some of the basic dosimetric parameters. With these parameters, the physicist or the radiotherapy planner can evaluate the profile and absorbed dose distributions from a particular beam. The Fricke Xylenol Gel (FXG) dosimeter is an alternative chemical dosimetric system for dosimetric parameters evaluation ${ }^{(2,3)}$. This chemical dosimeter is based on the standard chemicals of Fricke solution ${ }^{(4)}$ where the porcine skin gelatin and the xylenol orange dye (XO) are added. This composition has $\mathrm{Fe}^{+2}$ ions, once it's irradiated, it will oxidize to $\mathrm{Fe}^{+3}$, forming the XO-Fe complex bond, which shows a linearity with the absorbed dose when it is measured by a spectrophotometric system at a range of 575 to $585 \mathrm{~nm}^{(5)}$. The FXG dosimeter can present reproducibility and accuracy ${ }^{(3)}$. In this work the Fricke Xylenol Gel (FXG) is used to measure the dose response (calibration curve) and some physical parameters such as the open and wedged X-ray beam profiles, open electron beam profiles and X-ray output factor for two X-ray energies ( 6 \& $15 \mathrm{MV}$ ) and two electron energies $(6 \& 15 \mathrm{MeV})$. The FXG has some interesting features such as, broad linear dependence with the absorbed dose from 0.5 up to 30 Gy for $\gamma$ and $x$-ray photons ${ }^{(5-7)}$. All these absorbance measurements are done with a visible spectrophotometric technique ${ }^{(8,9)}$. The same measurements are made with ionization chambers, and others are done with a daily quality assurance machine to compare the results.

\section{Materials and Methods}

\section{FXG preparation, filling and analysis}

All batches of FXG solutions were prepared using $4 \%$ by weight 300 Bloom gelatin from porcine skin Type A G 2500 Sigma-Aldrich, highly purified deionized water, $50 \mathrm{mM}$ sulphuric acid $\left(\mathrm{H}_{2} \mathrm{SO}_{4}\right), 1 \mathrm{mM}$ ferrous ammonium sulphate hexahydrate $\left[\mathrm{Fe}\left(\mathrm{NH}_{4}\right)_{2}\left(\mathrm{SO}_{4}\right)_{2} \cdot 6 \mathrm{H}_{2} \mathrm{O}\right]$ and $0.1 \mathrm{mM}$ xylenol orange, $(\mathrm{C} 31 \mathrm{H} 28 \mathrm{~N} 2 \mathrm{Na} 4 \mathrm{O} 13 \mathrm{~S})^{(10)}$. The gelatin water mixture contributes $80 \%$ of the final volume, and the active chemicals make up to $20 \%$. The Gelatin powder was mixed with Deionized water and heated in water bath at $40^{\circ} \mathrm{C}$ and left for about $15 \mathrm{~min}$ to be absorbed. Then the water-gelatin mixture was heated and continuously stirred with a magnetic stirrer until the powder was completely dissolved, giving clear solution at about $45^{\circ} \mathrm{C}$. After mixing, The chemicals were prepared by adding sulphuric acid, then ferrous ions were dissolved in the acidic water and finally Xylenol orange was added. Immediately after preparation, the dosimetric solutions were conditioned in PMMA cuvettes with the following characteristics $^{(11)}$ : two parallel optical faces, $10 \mathrm{~mm}$ of optical path length of dimensions $10 \times 10 \times 45 \mathrm{~mm}^{3}$. The cuvettes were sealed with parafilm and placed in a refrigerator for about $24 \mathrm{hr}$, in order to obtain solid and stable gel samples for the spectrophotometric measurements. The spectrum analysis and optical density of FXG gel were measured using double beam SPECORED ${ }^{\circledR}$ spectrophotometer through the wavelength range $200-1100 \mathrm{~nm}$. It was operated in absorbance mode, and changes of optical density in $1 \mathrm{~cm}$ path length FXG samples were measured at a fixed wavelength of $585 \mathrm{~nm}$. Three exposures for

Egypt. J. Biophys. Biomed . Engng. Vol. 17 (2016) 
one point were done with the daily QA machine, and three samples were used for each FXG measurement. FXG measurements were performed within 30 to 40 minutes after irradiations to avoid the diffusion effects ${ }^{(6)}$.

\section{The comparable materials}

In this study, the measurements are made with the FXG chemical dosimeter and the results are compared with a daily check device and ionization chamber. Daily $\mathrm{QA}^{\mathrm{TM}} 3$ machine SUNNUCLEAR ${ }^{\odot}$ is used to measure open and wedged radiation beam profiles. This machine contains 13 distributed ionization chambers for X-ray and electron beams and 12 SunPoint ${ }^{\circledR}$ diode detectors in different points (Fig. 1), $0.3 \mathrm{~cm}^{3}$ is the active area of X-ray chambers while 0.6 $\mathrm{cm}^{3}$ is the active area of electron chambers. This machine also is calibrated by cross calibration with a calibrated ionization chamber. For the dose calibration curve and the output factors, the FXG is used and the results were compared with ionization chambers. The IBA FC65-G $G^{\circledR}$ Farmer ionization chamber with 0.65 $\mathrm{cm}^{3}$ cavity volume and $\mathrm{N}_{\mathrm{DW}}=4.820 \times 10^{7} \mathrm{~Gy} / \mathrm{C}$ is used for X-ray beams, while IBA PPCO5 ${ }^{\circledR}$ parallel plate ionization chamber with 0.05 active volume and $\mathrm{N}_{\mathrm{DW}}$ $=54.45 \times 10^{7} \mathrm{~Gy} / \mathrm{C}$ is used for electron beams. The $I B A S P 22^{\circledR}$ solid plates phantom made from PMMA are used for all measurements. A $30 \times 30 \times 4.2 \mathrm{~cm}^{3}$ of PMMA phantom is used as a buildup region of measurements while a $30 \times 30 \times 10$ $\mathrm{cm}^{3}$ under the examined samples (or QA machine / ion chambers) to avoid a scattered dose (Fig. 2).

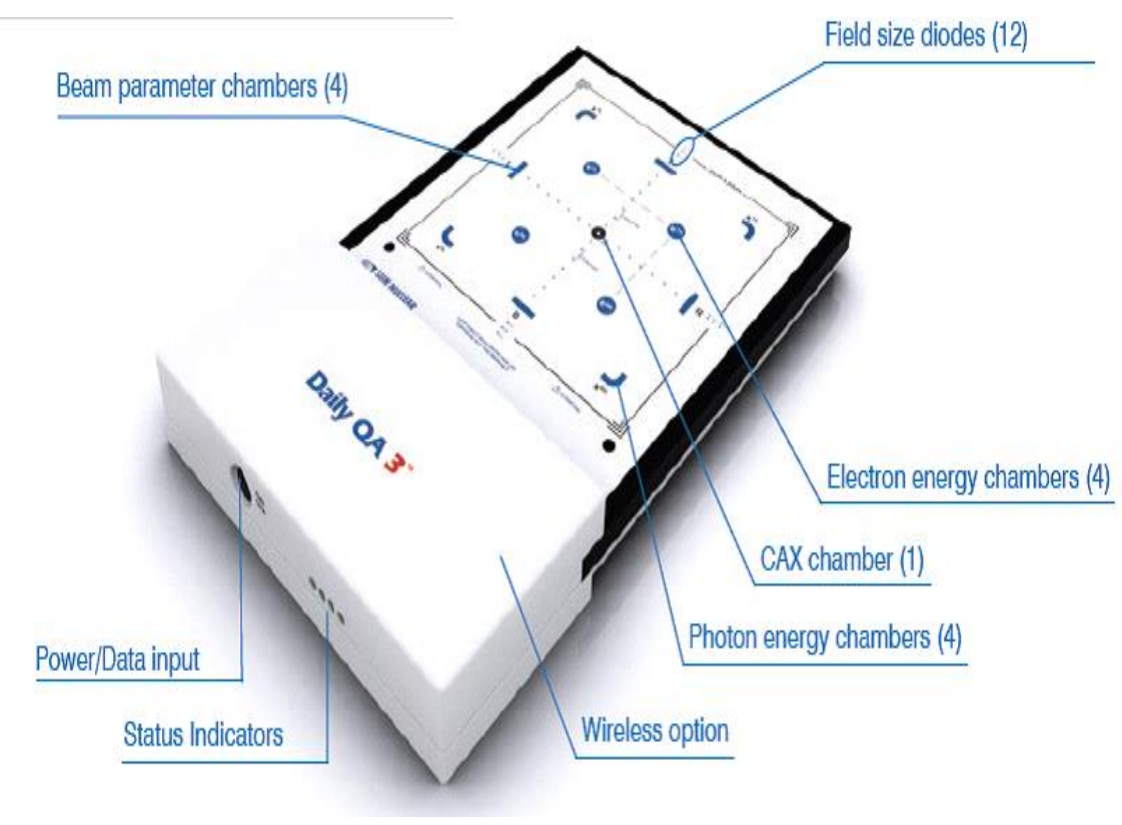

Fig. 1. The SUNNUCLEAR Daily $\mathbf{Q A}^{\mathrm{TM}}$ instrument. 


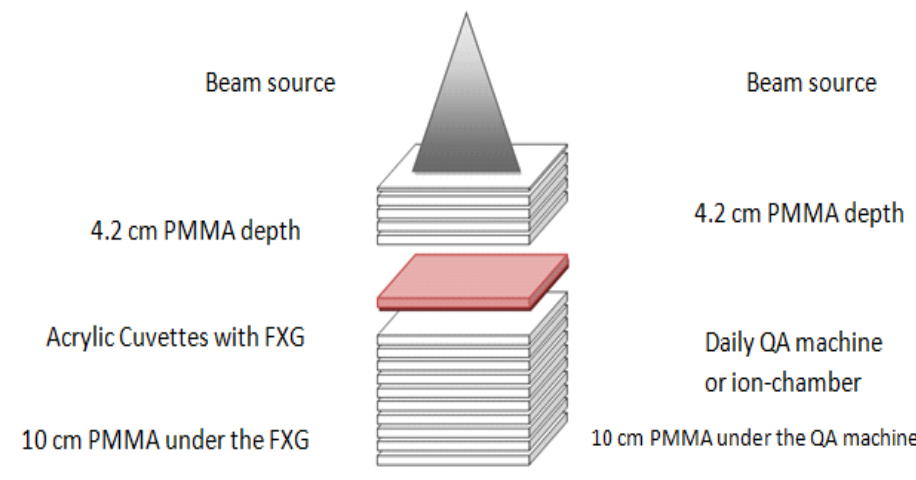

(a)

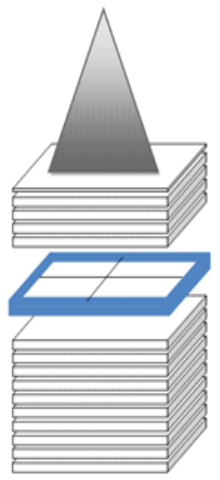

(b)

Fig. 2. Setup with PMMA phantom for open and wedged $X$-ray beam profiles, open electron beam profiles and $X$-ray output factor with 4 plates $30 \times 30 \times 1 \mathrm{~cm}^{3}$ and one plate $30 \times 30 \times 0.2 \mathrm{~cm}^{3}$ up and 10 plates $30 \times 30 \times 1 \mathrm{~cm}^{3}$ down to the examined FXG samples (a) or daily QA machine (b).

The setup of treatment machine

These measurements are irradiated with 6 and $15 \mathrm{MV}$ X-ray beams and 6 and $15 \mathrm{MeV}$ Electron beams by a LINAC ELEKTA Precise ${ }^{\circledR}$. For the X-ray beams, the setup is done at isocentric technique at source to axis distance (SAD) $100 \mathrm{~cm}$, 0 gantry, 0 collimator, $4.2 \mathrm{~cm}$ depth and different field size according to the type of measurement, while the electron beam setup is done at source to surface distance (SSD) $100 \mathrm{~cm}, 0$ gantry angle, 0 collimator angle, applicator $10 \mathrm{X} 10$ and at depth of maximum dose $\left(D_{\max }\right)$. Three FXG samples are used in each irradiation and the delivered doses are fixed or increased according to the measurement. The irradiation is done after one day or a few hours of the preparation of FXG and then the optical absorption is measured within the first hour of irradiation.

\section{Dose response}

With respect to the FXG dosimeter, the Dose response or the calibration curve is a relationship between the absorbed dose and the color change of FXG due to the exposure to radiation. The measurements are done at field size $10 \times 10$ for X-ray and applicator, $10 \times 10$ for electron measurements. An ideal dosimeter presents a linear behavior between its readings and the absorbed doses ${ }^{(12)}$. In this study, the calibration curves are obtained with the dosimeters to compare their behavior. The FXG samples are irradiated with 1, 3, 5, 10 and 15 Gy for X-ray and 1, 3, 6 and $9 \mathrm{~Gy}$ for electron measurements. The reading of ion-chamber absorbed dose actually appears as charges and the values of these charges dependent on the value of doses ${ }^{(13)}$.

Egypt. J. Biophys. Biomed. Engng. Vol. 17 (2016) 
Open and wedged beam profiles

The beam profiles are obtained through square field size $20 \times 20$ and applicator, $20 \times 20$ for $\mathrm{X}$-ray and electron beam, respectively. The wedged beams are applied only in X-ray measurements and not applicable in electron beam. So in this study, open and wedged beam profiles are done in the X-ray beam, while the normal electron beam profiles (those are already opened and not wedged) are also performed. According to Elekta Linac, the measurements of wedged beams are done for motorized wedge at $60^{\circ}, 45^{\circ}, 30^{\circ}$ and $15^{\circ}$. For 6 and $15 \mathrm{MV}$, The profile evaluations are performed with an SAD of $100 \mathrm{~cm}$ and both dosimeters (FXG \& daily QA) are positioned at $4.2 \mathrm{~cm}$ depth while for 6 and $15 \mathrm{MeV}$ the setup at SSD 100 and depths 1.2 and $2.1 \mathrm{~cm}$ of PMMA, respectively (Fig. 2). The beam profile is a curve showing the flatness and symmetry of both sides of measured points of beam normalized to the central point measurement. Any beam profile has two types of measurements; one is horizontal with treatment table called "in-plan direction" and other perpendicular called "cross-plan". Both directions of profile measurements are done. Daily $Q A^{\mathrm{TM}} 3$ can measure the profile at five points, each point has an ionization chamber, one of these chambers in the central axis and two in in-plan direction at $8 \mathrm{~cm}$ of axis and the others in cross-plan direction at $8 \mathrm{~cm}$ of axis (Fig.1). The FXG optical density measurements are made at the same positions of daily $Q A^{\mathrm{TM}} 3$ points. The beam profile values, for $\mathrm{FXG}$, are compared with the values daily $Q A^{\mathrm{TM}} 3$ and normalized with the radiation field center value (maximum absorbed dose value), according to the following equation:-

$$
\text { The beam profile }=\left(R_{d} / R_{c}\right) * 100
$$

where $R_{d}$ is the reading of absorbed dose at a point along the field and $R_{c}$ is the reading of absorbed dose at the central axis ${ }^{(14)}$. The percentage difference between the two values can be calculated according to the equation:

Diff $\%=(($ Daily $Q A$ machine value $-\mathrm{FXG}$ value $) /$ Daily QA machine value $)) \times$ 100 .

According to this equation, the daily $Q A$ machine's values are taken as references for the FXG values.

\section{Total scatter factors (TSF)}

Sometimes the total scatter factor (TSF) is called the field size factor or output factor. This factor is the ratio of dose value delivered from a prescribed field size at the central axis point to the dose value of calibration condition of field size at the same point. Generally, in the radiotherapy, the reference condition of field size is $10 \times 10 \mathrm{~cm}$. so, the output factor can be calculated according to the following equation :

The output factor $=D_{f} / D_{10}$, where i $D_{f}$ the absorbed dose value for selected field size while, $\mathrm{D}_{\mathrm{r}}$ the absorbed dose value for reference filed size ${ }^{(14)}$. 
The field size factors are acquired for both dosimeters and all energies values. The measured data were done for $5,10,20,30$ and 40 equivalent field size. For X-ray beam and applicator $6 \times 6,10 \times 10,14 \times 14,20 \times 20$ and $25 \times 25$ for electron beams, the determination of output factor is very important for dose calculation because the treatment dose may be varied according to this value.

\section{Results and Discussion}

\section{Results of dose response}

Figure 3 shows dose response of FXG for the four energies (two X-ray and two electron beam). The absorbance change or the net absorbance shows that for the 6 and $15 \mathrm{MeV}$, the sensitivity equals 0.085 and $0.088 \mathrm{~Gy}^{-1} \mathrm{~cm}^{-1}$, respectively in the range of 1 to $9 \mathrm{~Gy}$, while in the X-ray the sensitivity for both 6 and 15 $\mathrm{MV}$, are equal to $0.68 \mathrm{~Gy}^{-1} \mathrm{~cm}^{-1}$ for range from 1 to $15 \mathrm{~Gy}$. On the other hand, Fig. 3 indicates that the energy dependent response appeared in electron beams while it is independent on X-ray beam energies. Figure 4, shows the calibration curve of the ionization chamber for the electron beam energies are almost independent and is dependent for the X-ray energies.

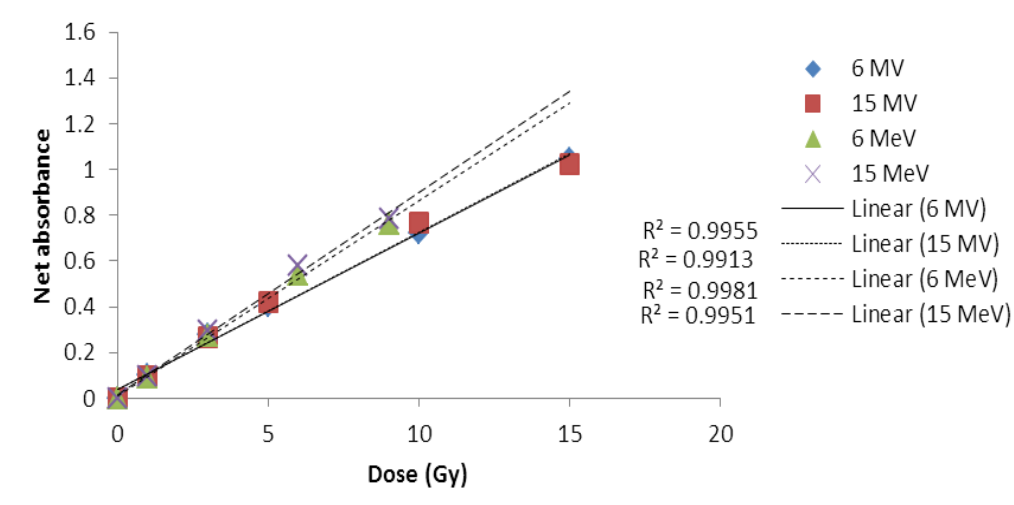

Fig. 3. The FXG dose response of $6,15 \mathrm{MV}$ X-ray and $6,15 \mathrm{MeV}$ electron energies.

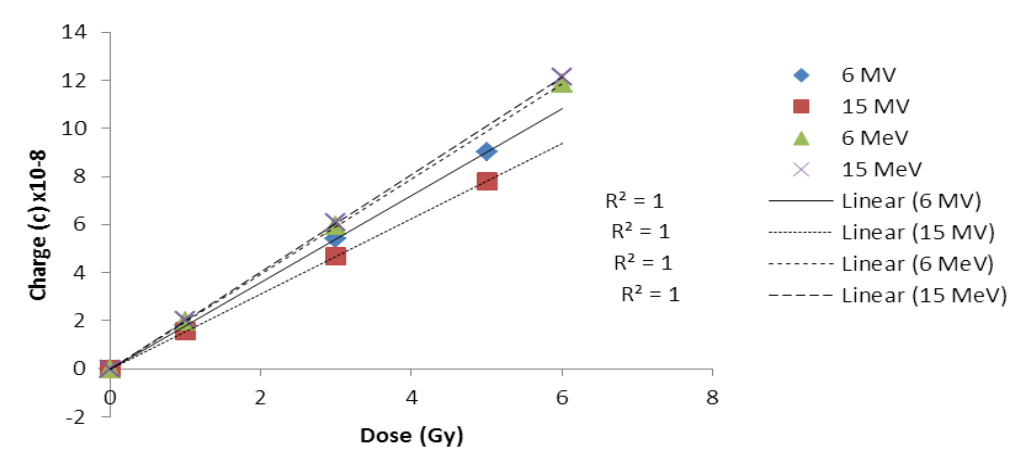

Fig. 4. The ionization chamber dose response of 6, $15 \mathrm{MV}$ X-ray and 6, $15 \mathrm{MeV}$ electron energies.

Egypt. J. Biophys. Biomed. Engng. Vol. 17 (2016) 


\section{Results of beam profiles}

Open beam profile

Figures 5-A, B, C and D show the open beam profile for energies $6 \mathrm{MV}, 15 \mathrm{MV}$, $6 \mathrm{MeV}$ and $15 \mathrm{MeV}$, respectively for both dosimeters (Daily QA and FXG). Figure 5-A shows the comparison of both dosimeters for $6 \mathrm{MV}$ in cross and in plan directions, for the cross-plan direction the difference between the two dosimeters at the same point was $0.03 \%$ at the right side while $2.05 \%$ at the left side. In the in-plan direction, the difference is $0.46 \%$ and $1.14 \%$ for both inferior and superior sides, respectively.

Related to the profiles of $15 \mathrm{MV}$, Fig. 5-B shows the beam profiles for both dosimeters (Daily QA and FXG) and the results record almost very small difference between each other (for the cross-plan, $1.33 \%$ at the right side and $0.9 \%$ at the Left side, while for the in-plan direction, the difference is $1.87 \%$ and $0.48 \%$ for both inferior and superior sides, respectively). Generally the mean difference between the two dosimeters is $1.00 \%$ for X-ray beam profiles.

For electron beam profiles, the results are shown in Fig. 5-C and D. In Fig. 5$\mathrm{C}$, the beam profile is measured for energy $6 \mathrm{MeV}$ and the difference between the daily QA and gel dosimeters in cross plan direction is $2.04 \%$ and $1.2 \%$ in right and left side, respectively, while the difference is $2.74 \%$ and $1.60 \%$ in inferior and superior sides, respectively.

Figure 5-D shows the shape of beam profiles for both dosimeters for $15 \mathrm{MeV}$ electron beam and the difference between them for cross-direction are $2.43 \%$ and $2.00 \%$ for right and left side, respectively, while in the in-plan direction the difference is $2.20 \%$ and $2.74 \%$ for inferior and superior sides, respectively. From these results the mean difference between both dosimeters (Daily QA machine and Fricke gel dosimeters) is $2.11 \%$ for electron beam profiles.

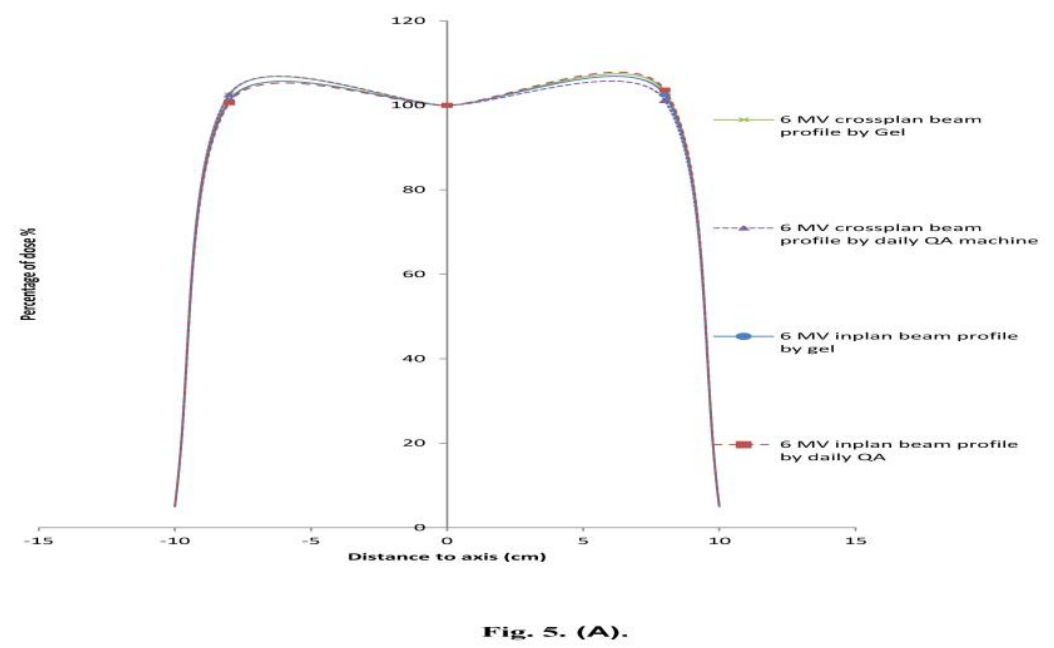

Egypt. J. Biophys. Biomed. Engng. Vol. 17 (2016) 


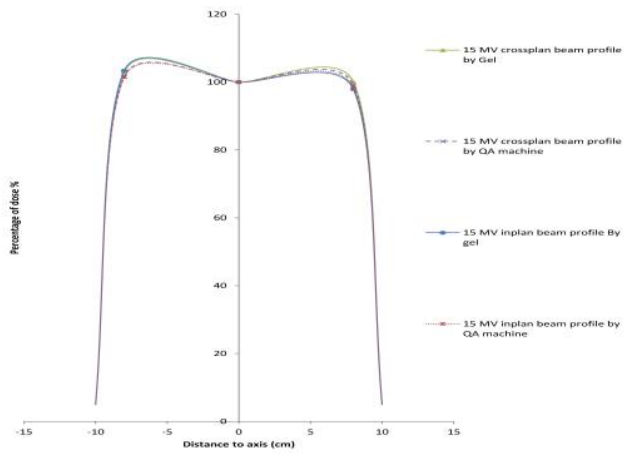

Fig. 5.(B)
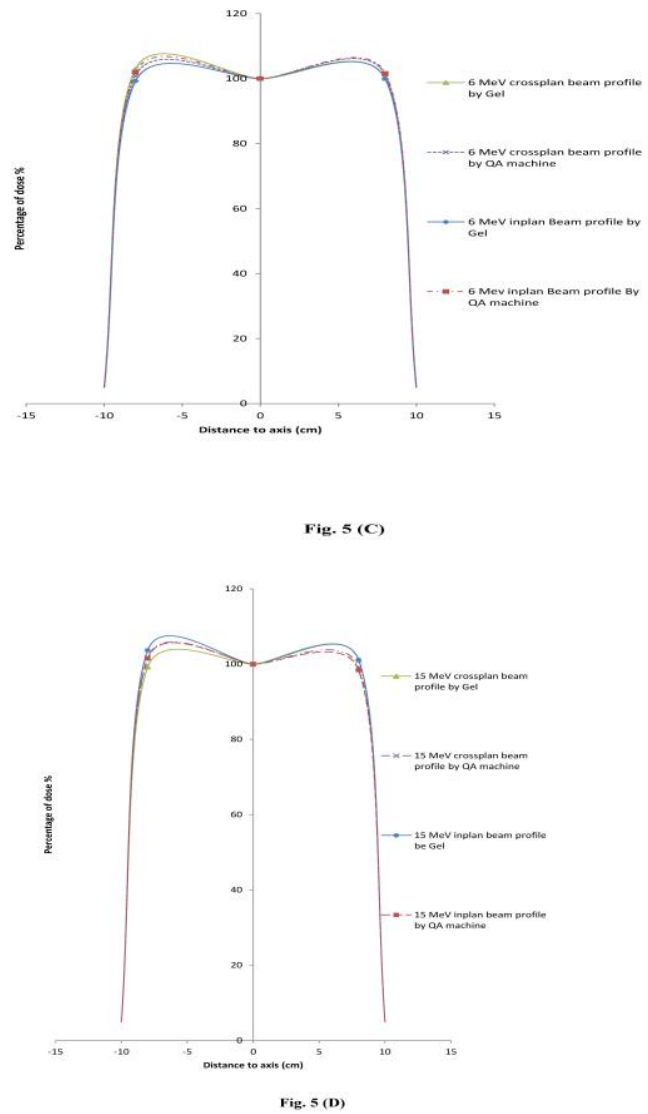

Fig. 5. The beam profiles for both in and cross plan of FXG and daily QA machine for (A) , (B) beam profiles for $6 \mathrm{MV}$ and $15 \mathrm{MV} \mathrm{X}$-ray beams respectively, (C), (D) beam profile for $6 \mathrm{MeV}$ and $15 \mathrm{MeV}$, respectively.

Egypt. J. Biophys. Biomed. Engng. Vol. 17 (2016) 
$X$-Ray wedged beam profiles

Figures 6 and 7 show the shapes of 6,15 wedged beam profiles, respectively for angles $60^{\circ}, 45^{\circ}, 30^{\circ}$ and $15^{\circ}$ measured by both dosimeters FXG and daily QA machine. Tables 1 and 2 show the difference percentage between the dosimeters during these measurements for 6 and 15 wedged X-ray beam profiles, respectively.

TABLE 1. The percentage difference values between the two dosimeters in $6 \mathrm{MV}$ wedged $\mathrm{X}$-ray beam profiles for different wedge angles.

\begin{tabular}{|c|c|c|c|}
\hline & \multicolumn{2}{|c|}{ \%Diff. between the two dosimeters at right and left side } & \multirow{2}{*}{$\begin{array}{c}\text { Mean } \\
\text { Diff. }\end{array}$} \\
\cline { 2 - 3 } & Left side & Right side & 0.54 \\
\hline Wedge $60^{\circ}$ & 0.04 & 1.03 & 1.99 \\
\hline Wedge $45^{\circ}$ & 2.11 & 1.86 & 2.10 \\
\hline Wedge $30^{\circ}$ & 1.31 & 2.88 & 2.28 \\
\hline Wedge $15^{\circ}$ & 1.92 & 2.64 & \\
\hline
\end{tabular}

TABLE 2. The percentage difference values between the two dosimeters in $15 \mathrm{MV}$ wedged $X$-ray beam profiles for different wedge angles.

\begin{tabular}{|c|c|c|c|}
\hline & \% Diff. between the two dosimeters at right and left side & Mean \\
\cline { 2 - 4 } & Left side & Right side & Diff. \\
\hline Wedge $60^{\circ}$ & 0.32 & 1.38 & 0.85 \\
\hline Wedge $45^{\circ}$ & 2.80 & 1.14 & 1.97 \\
\hline Wedge $30^{\circ}$ & 0.87 & 1.51 & 1.19 \\
\hline Wedge $15^{\circ}$ & 2.03 & 2.64 & 2.34 \\
\hline
\end{tabular}

From these tables the range of difference between both dosimeters (Daily QA machine and Fricke gel dosimeters) is about 1 to $2.3 \%$ in wedged beam profiles for 6 and $15 \mathrm{MV}$.

\section{Results of output factor}

Figures 8 and 9 show the output curve of output factors for 6 and 15 MV X-ray beams delivered from equivalent square field size $5,10,15,20,30$ and $40 \mathrm{~cm}^{2}$ while Fig. 10 and 11 show the output curve of output factor for 6 and $15 \mathrm{MeV}$ electron beam for applicators $6 \times 6,10 \times 10,14 \times 14,20 \times 20$ and $25 \times 25 \mathrm{~cm}^{2}$. All these values are measured by both dosimeters (Ionization chambers and FXG). The reading of doses for both dosimeters according to all field size are normalized to the dose value of $10 \times 10$ which is considered the reference condition of measurements. In general, the larger the surface field sizes the more scattered radiation ${ }^{(15)}$, so that, the output factor will be increased with increasing field size close to equilibrium. From formerly shown figures, the range of difference between two dosimeters are from 1 to $3.2 \%$ for $6 \mathrm{MV}$ and 0.3 to $2.1 \%$ for $15 \mathrm{MV}$ and the mean difference is $1.66 \%$ for $6 \mathrm{MV}$ and $1.22 \%$ for $15 \mathrm{MV}$. 


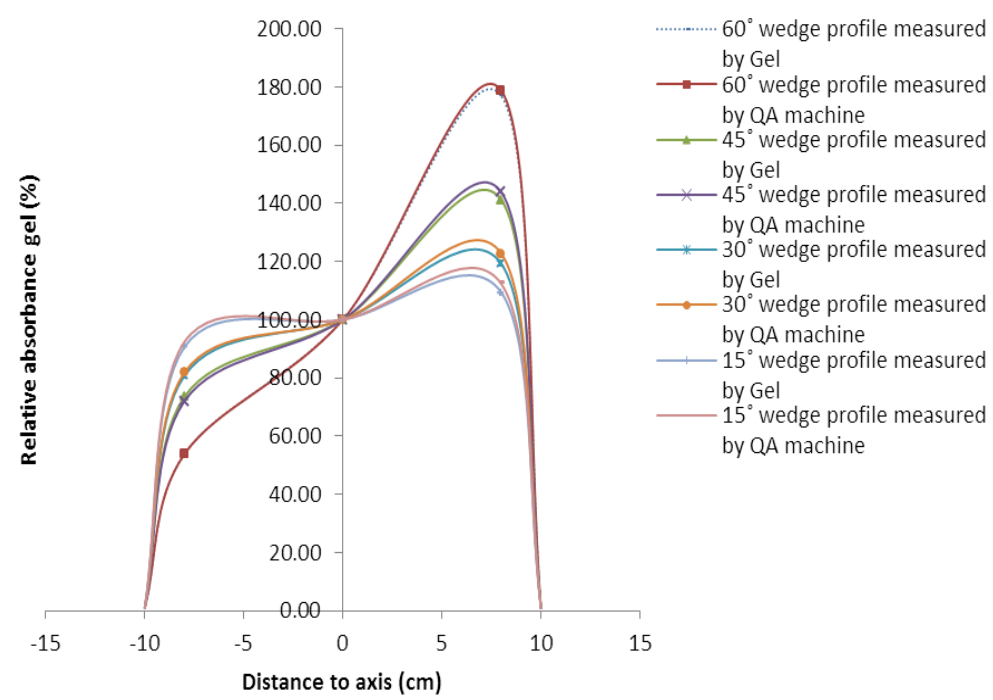

Fig.6. $6 \mathrm{MV}$ wedged beam profile for angles $60^{\circ}, 45^{\circ}, 30^{\circ}$ and $15^{\circ}$ degree for daily QA and Gel dosimeters.

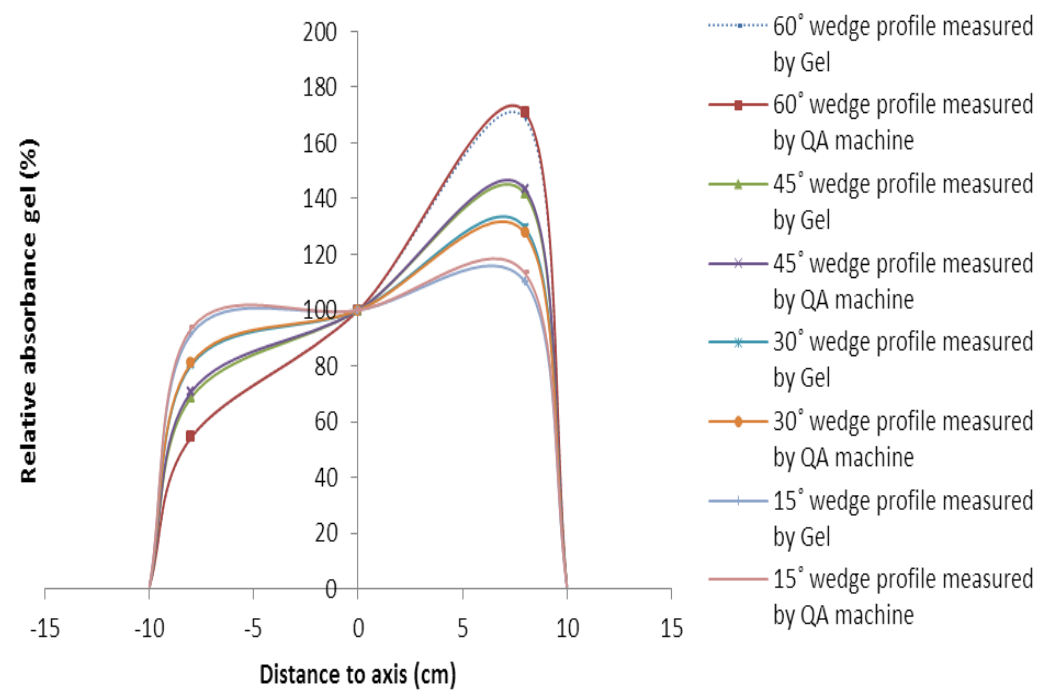

Fig.7. $15 \mathrm{MV}$ wedged beam profile for angles $60^{\circ}, 45^{\circ}, 30^{\circ}$ and $15^{\circ}$ degree for daily QA and Gel dosimeters.

Egypt. J. Biophys. Biomed. Engng. Vol. 17 (2016) 


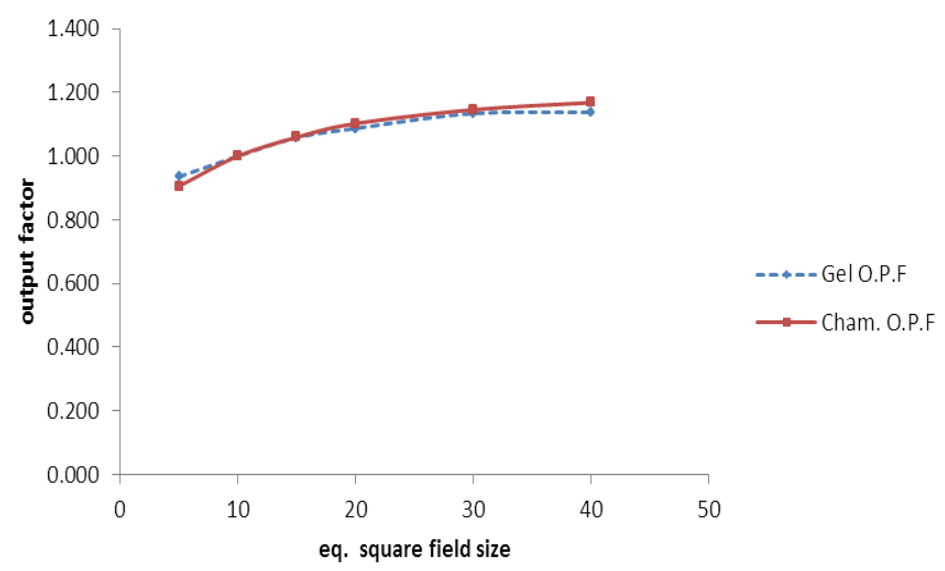

Fig.8. The output factor of $6 \mathrm{MV}$ X-ray beam measured by Gel and ionization chamber (Cham).

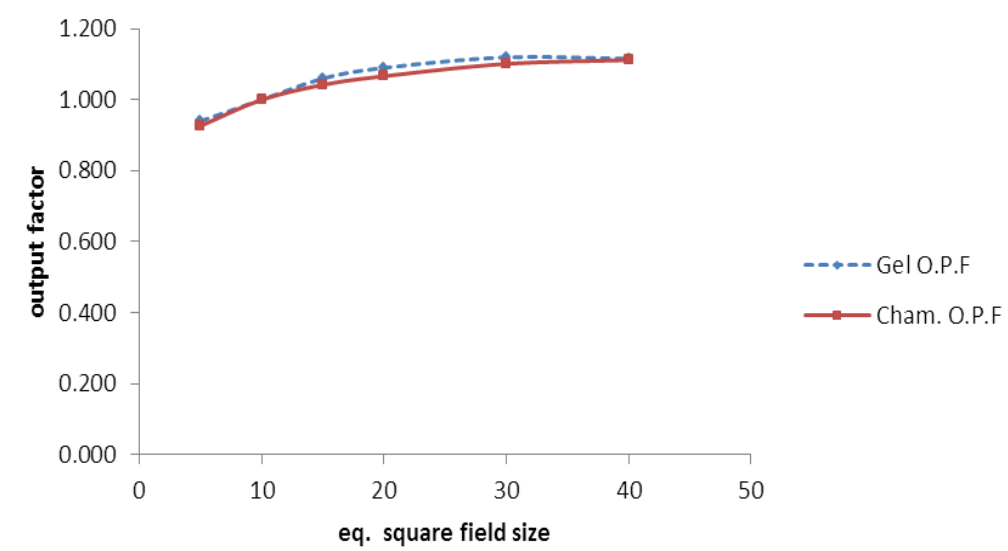

Fig.9. The output factor of $15 \mathrm{MV} \mathrm{X}$-ray beam measured by Gel and ionization chamber (Cham).

For the electron beam, of $15 \mathrm{MeV}$ shows a higher electronic disequilibrium influence than $6 \mathrm{MeV}$ because in the lower value of energy; the scattered electrons' contribution in the water is lower ${ }^{(16)}$, which can be seen in presnet results. From Fig. 10 and 11, there is a small difference between the two dosimeters, the difference range is from $1 \%$ to $1.6 \%$ and 1.33 to $2.4 \%$ and the mean difference is $1.5 \%$ and $1.4 \%$ for $6 \mathrm{MeV}$ and $15 \mathrm{MeV}$, respectively. 


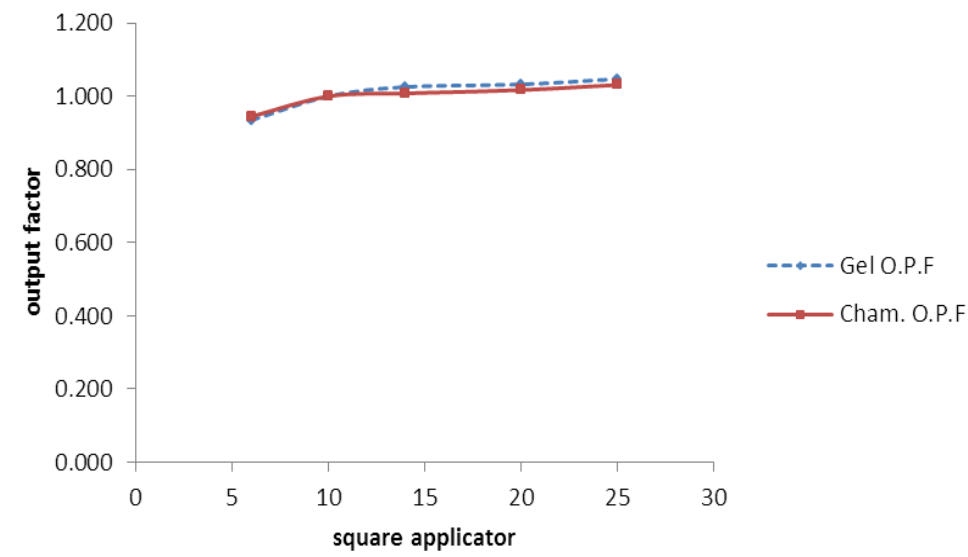

Fig.10. The output factor of $6 \mathrm{MeV}$ electron beam measured by Gel and ionization chamber (Cham).

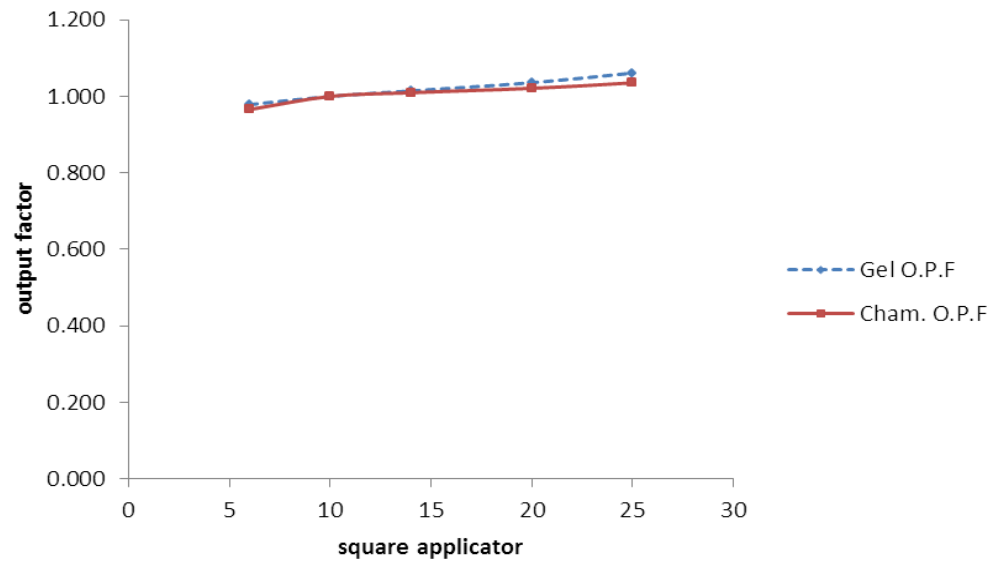

Fig.11. The output factor of $15 \mathrm{MeV}$ electron beam measured by Gel and ionization chamber (Cham).

\section{Conclusion}

- In the calibration curve, the FXG represents a linear behavior and the sensitivity is equals to $0.86 \mathrm{~Gy}^{-1} \mathrm{~cm}^{-1}$ for electron beams in the range from 1 to $9 \mathrm{~Gy}$, While the sensitivity is almost $0.68 \mathrm{~Gy}^{-1} \mathrm{~cm}^{-1}$ for range from 1 to 15 $\mathrm{Gy}$ in the photon beam for the measured range of energy.

Egypt. J. Biophys. Biomed. Engng. Vol. 17 (2016) 
- The FXG can be used as a check for beam profile dosimeter, because the mean difference between the daily QA machine and the FXG in photon beams is $1 \%$, and $2.11 \%$ in electron beam.

- Also, the wedged beam profile shows no difference between the standard and FXG dosimeters for different angles, whereas the mean difference is not more than $2.5 \%$.

- The total scatter factor values which are measured with FXG and the ionization chamber record some differences between the two dosimeters and are found to be 1 to $1.6 \%$ and 1.33 to $2.4 \%$.

- Therefore, the FXG applicability is valid, because it represents minimum differences in the dosimetric parametric of radiotherapeutic treatment.

\section{References}

1. International Commission on Radiation Units and Measurements (ICRU), Prescribing, recording, and reporting electron beam therapy. $J$. ICRU, 4,(1), 3-100 (2004).

2. Luis, F.P., Marcos, V.M., Jhonatha, J.L.C., Lucas, N.O., Linda, V.E.C. and Adelaidede A., "Fricke dosimeter gel measurements of the profiles of shielded fields". Applied Radiation and Isotopes, 82, 239-241 (2013).

3. Maeyama. T., Fukunishi. N., Ishikawa. K.L., Furuta. T., Fukasaku. K., Takagi. S., Noda. S., Himeno. R. and Fukuda. S., "A diffusion free and linear energy transfer independent nanocomposite Fricke gel dosimeter". Radiation Physics and Chemistry, 96, 92-96 (2014).

4. International Atomic Energy Agency (IAEA), "Absorbed dose determination in external beam radiotherapy: An international code of practice for dosimetry based on standards of absorbed dose to water," Vienna, Austria, Tech. Rep. Ser No. 398 (2000).

5. Caldeira, A.M.F., De Almeida, A., Neto, A.M., Baesso, M.L., Bento, A.C., and Silva, M.A., "Fricke Xylenol Gel characterization using a photoacustic technique," Nucl. Instr. Meth. Phys. A, Vol. 582, pp. 484-488 (2007).

6. De Oliveira, L.N., Zimmerman, R.L., Moreira, M.V., Ila. D. and De Almeida, A., "Determination of diffusion coefficient in Fricke Xylenol Gel dosimeter after electron beam bombardment". Surf. Coa. Technol., 203, $2367-2369$ (2009).

7. Joint Committee for Guides in Metrology 100, "Evaluation of measurement Data Guide to the expression of uncertainty in measurement" Geneva, Switzerland, Tech. Rep. Int. Organiz. Standard (2008). 
8. Hogstrom, K.R., and Almond, P.R., Review of electron beam therapy physics. Phys. Med. Biol. 51, (13), 455-489 (2006).

9. Rashid, H., Islam, M.K., Gaballa, H., Rosenow, U.F. and Ting, J.Y., Small-field electron dosimetry for the philips SL25 linear accelerator. Med. Phys., 17, (4), 710-714 (1990).

10. Sampaio. F.G.A., deOliveira. L.N., Moreira. M.V., Petchevist. P.C.D., deAlmeida. C.E. and de Almeida. A., 8 and $10 \mathrm{MeV}$ electron beams small field-size dosimetric parameters through the Fricke Xylenol Gel dosimeter. IEEE. Trans. Nucl. Sci., 60, (2), (2013)a.

11. Sampaio, F.G.A., Del Lama, L.S., Sato, R., de Oliveira, D.M.M., Czelusniak, C., Oliveira, L.N. and de Almeida, A., "Quality assurance of a two-dimensional ccd detector system applied in dosimetry. IEEE. Trans. Nucl. Sci. 60, (2), (2013)b.

12. Attix, F.H., "Introduction to Radiological Physics and Radiation Dosimetry", Weinheim, Germany: Wiley-VCH Verlag GmbH and Co. KGaA, 277-284 (2004).

13. International Atomic Energy Agency (IAEA), “Absorbed dose determination in external beam radiotherapy: An international code of practice for dosimetry based on standards of absorbed dose to water". Tech. Rep. Ser 398 (2000).

14. Khan, F.M., Doppke, K., Hogstrom, K.R., Kutcher, G.J., Nath, R., Prasad, S.C., Purdy, J.A., Rozenfeld, M., and Werner, B.L., "Clinical electron beam dosimetry: Report of AAPM radiation therapy committee task group no. 25". Med. Phys., 18, (1), 73-79 (1991).

15. Amen S., Morgan, A. and Dougall, N. M., "Radiotherapy in Practice Physics for Clinical Oncology”. Oxford University Press, pp.100-101 (2012).

16. Wu, A., Zwicker, R.D., Kalend, A.M. and Zheng, Z., Comments on dose measurements for a narrow beam in radiosurgery. Med. Phys. 20, (3), 777780 (1993). 
RADIOTHERAPY MEASUREMENTS USING FRICKE GEL DOSIMETER 15 قياسات العلاج الإشعاعى بإستخدام مقياس الجرعة الجيلاتينى

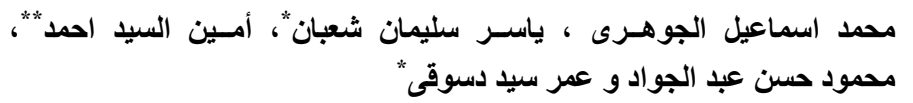

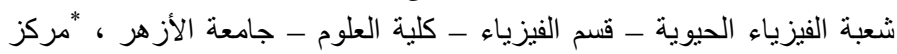

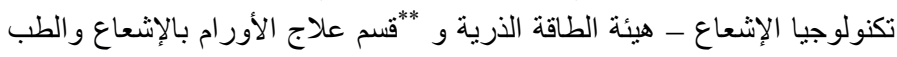

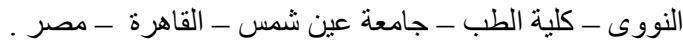

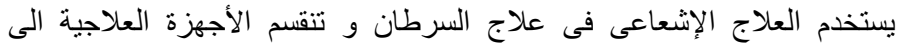

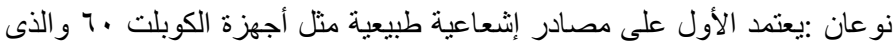

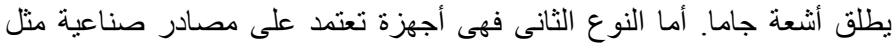

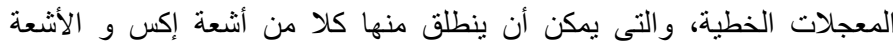

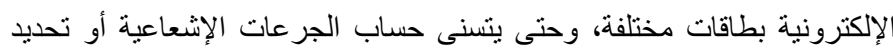

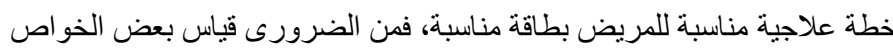
اللتأكد من مناسبة وكمية هذه الطاقة للعلاج .

فيى هذا البحث، تم قياس بعض هذه الخواص مثل منحنى المعايرة، وشكل

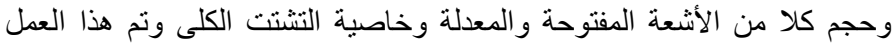

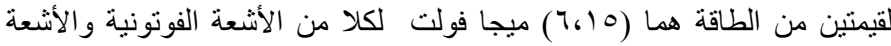

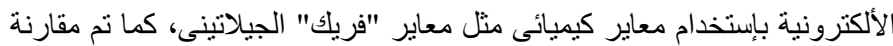
القياسات بإستخدام أجهزة معايرة أخرى مثل غرف التأين و أجهزة المعايرة اليومية.

وكان الهذف من هذا البحث هو تقييم معاير فريك لكى يستخدم لقياس هذه الخواص ويصبح هذا المعاير بديل لأجهزة المعايرة اليومية.

أظهرت النتائج أنه عند قياس هذه الخو اص بإستخدام نظام غرف التأين كمعاير

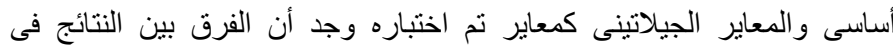

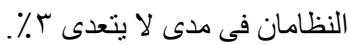

